\title{
Retraction Note to: Integration of Eco-Friendly POF-Based Splitter and Optical Filter for Low-Cost WDM Network Solutions
}

\author{
Archana Rathore
}

\author{
Retraction Note to: \\ Chapter "Integration of Eco-Friendly POF-Based Splitter \\ and Optical Filter for Low-Cost WDM Network Solutions" \\ in: D. P. Mohapatra and S. Patnaik (eds.), \\ Intelligent Computing, Networking, and Informatics, \\ Advances in Intelligent Systems and Computing 243, \\ https://doi.org/10.1007/978-81-322-1665-0_40
}

The Editors have retracted this chapter [1] because it overlaps substantially with a previous publication by Mohammad Syuhaimi, Ab-Rahman, Hadi Guna, Mohd Hazwan Harun, Latifah Supian and Kasmiran Jumari [2]. The author has not responded to any correspondence from the publisher about this retraction.

[1] Rathore A. (2014) Integration of Eco-Friendly POF-Based Splitter and Optical Filter for Low-Cost WDM Network Solutions. In: Mohapatra D., Patnaik S. (eds); Intelligent Computing, Networking, and Informatics. Advances in Intelligent Systems and Computing, vol 243. Springer, New Delhi.

[2] Mohammad Syuhaimi, Ab-Rahman, Hadi Guna, Mohd Hazwan Harun, Latifah Supian and Kasmiran Jumari. Integration of Eco-Friendly POF Based Splitter and Optical Filter for Low-Cost WDM Network Solutions. In: Optical Fiber Communicationas and Devices. Edited by Moh Yamin, 2012, Intech, https://www. intechopen.com/books/optical-fiber-communications-and-devices/integration-of-ecofriendly-pof-based-splitter-and-optical-filter-for-low-cost-wdm-network-solutions.

The retracted version of this chapter can be found at https://doi.org/10.1007/978-81-322-1665-0_40 